University of Nebraska - Lincoln

DigitalCommons@University of Nebraska - Lincoln

Faculty Publications in Computer \& Electronics Electrical \& Computer Engineering, Department Engineering (to 2015)

2004

\title{
Two complex orthogonal space-time codes for eight transmit antennas
}

Le Chung Tran

University of Wollongong

J. Seberry

University of Wollongong

Yejing Wang

University of Wollongong

B. J. Wysocki

University of Wollongong

T. A. Wysocki

University of Wollongong, wysocki@uow.edu.au

See next page for additional authors

Follow this and additional works at: https://digitalcommons.unl.edu/computerelectronicfacpub

Part of the Computer Engineering Commons

Tran, Le Chung; Seberry, J.; Wang, Yejing; Wysocki, B. J.; Wysocki, T. A.; Xia, Tianbing; and Zhao, Ying, "Two complex orthogonal space-time codes for eight transmit antennas" (2004). Faculty Publications in Computer \& Electronics Engineering (to 2015). 6.

https://digitalcommons.unl.edu/computerelectronicfacpub/6

This Article is brought to you for free and open access by the Electrical \& Computer Engineering, Department of at DigitalCommons@University of Nebraska - Lincoln. It has been accepted for inclusion in Faculty Publications in Computer \& Electronics Engineering (to 2015) by an authorized administrator of DigitalCommons@University of Nebraska - Lincoln. 


\section{Authors}

Le Chung Tran, J. Seberry, Yejing Wang, B. J. Wysocki, T. A. Wysocki, Tianbing Xia, and Ying Zhao 


\section{Two complex orthogonal space-time codes for eight transmit antennas}

Le Chung Tran, J. Seberry, Yejing Wang, B.J. Wysocki, T.A. Wysocki, Tianbing Xia and Ying Zhao

Two new constructions of complex orthogonal space-time block codes of order 8 based on the theory of amicable orthogonal designs are presented and their performance compared with that of the standard code of order 8 . These new codes are suitable for multi-modulation schemes where the performance can be sacrificed for a higher throughput.

Introduction: Transmit antenna diversity can be accomplished with the use of space-time codes (STCs) [1]. Out of the STCs, space-time block codes (STBCs) developed from the amicable orthogonal designs [2] lead to the simplest receiver structures and minimum processing delays if combined with modulation schemes having complex signal constellations, such as in the case of quaternary phase shift keying (QPSK) or quadrature amplitude modulation (QAM). The simplest STBC based on amicable orthogonal designs is an Alamouti code [1] providing a transmission rate of 1 for the two transmit antenna system. STBCs based on amicable orthogonal designs, usually referred to as complex orthogonal STBCs, for a larger number of transmit antennas cannot provide the transmission rate of 1 but they are attractive nevertheless since they can provide a full diversity for the given number of transmit antennas and are usually simple to decode. There exist some complex orthogonal STBCs designs for four transmit antennas and eight transmit antennas, e.g. [3], providing the rates of $3 / 4$ and $1 / 2$, respectively. They are usually based on those amicable orthogonal designs where each variable is represented just once in a design. Hence, the code matrices have many zeros (50\% for eight transmit antennas) resulting in many time slots when no useful information is being transmitted. In this Letter, we introduce two new complex orthogonal STBCs for eight transmit antennas having less unused time slots. In the first of these new codes, one of the variables is repeated twice and in the second code, one variable is repeated four times per every transmit antenna. These properties can be further exploited to increase the code rate over $1 / 2$ using more sophisticated modulation schemes, where the higher number of information bits is associated with those signals that appear in more than one time slot per each antenna.

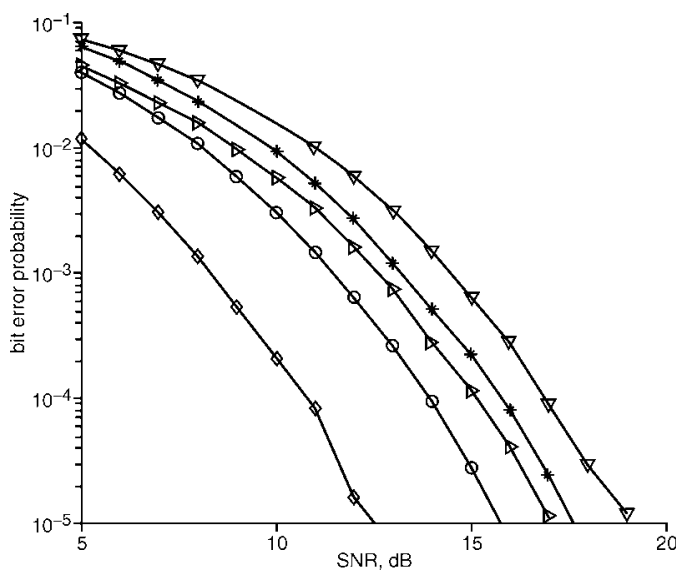

Fig. 1 Bit error performance of $S_{1}$ in single and multi-modulation schemes - - - code $S_{1}$, multimod, QPSK and 8 PSK

-*- code $S_{1}$, multimod, QPSK and 16 QAM

$-\diamond$ - code $S_{1}$, single-modulation, QPSK

$\rightarrow-$ reference code, multimod, QPSK and 8 PSK

$-\nabla-$ reference code, multimod, QPSK and 16 QAM

New codes and their performance: Orthogonal STBCs that can be used with complex signal constellations can be constructed using complex orthogonal designs (CODs) defined as follows.

Definition 1: A complex orthogonal design (COD) $\mathbf{X}$ of order $n$ is an $n \times n$ matrix on the complex indeterminates $s_{1}, \ldots, s_{t}$, with entries chosen from $0, \pm s_{1}, \ldots, \pm s_{t}$, their complex conjugates $\pm s_{1}^{*}, \ldots, \pm s_{t}^{*}$, or their linear combinations, such that

$$
\mathbf{X}^{H} \mathbf{X}=\left(\sum_{k=1}^{t}\left|s_{k}\right|^{2}\right) \mathbf{I}_{n}
$$

where $\mathbf{X}^{H}$ denotes the Hermitian transposition of $\mathbf{X}$ and $\mathbf{I}_{n}$ is the identity matrix of order $n$.

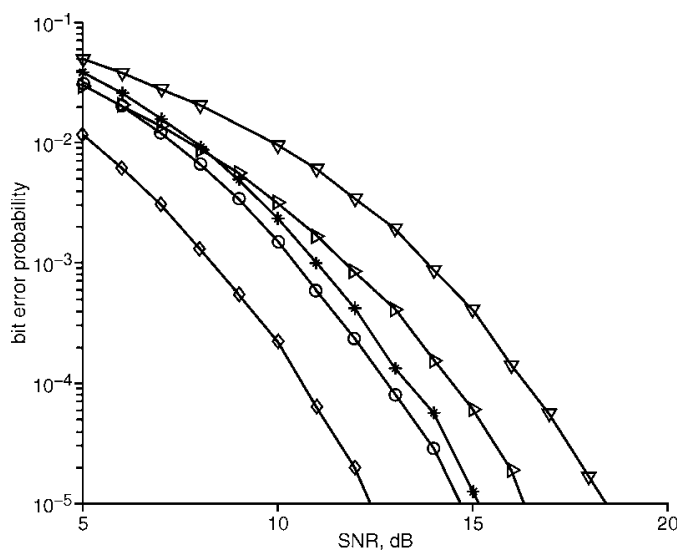

Fig. 2 Bit error performance of $S_{2}$ in single and multi-modulation schemes - - - code $S_{2}$, multimod, QPSK and 8 PSK

$-*-$ code $S_{2}$, multimod, QPSK and 16 QAM

$-\diamond-$ code $S_{2}$, single-modulation, QPSK

$\rightarrow-$ reference code, multimod, QPSK and 8 PSK

$-\nabla-$ reference code, multimod, QPSK and 16 QAM

CODs are strongly connected to the amicable orthogonal designs (AODs), which have been explained in [4]. The detailed theory of amicable orthogonal designs (AODs), including limitations on the number of different variables for the given design order can be found in [2]. Drawing from the theory of the existence of AODs presented there, we found two new CODs of order 8 . The first one, corresponding to the $\operatorname{AOD}(8 ; 1,1,2,2 ; 1,1,2,2)$, which indicates that the 8 columns of the matrix contain both real and imaginary parts of $s 1$ and $s 2$ once, and of $s 3$ and $s 4$ twice, is of the form:

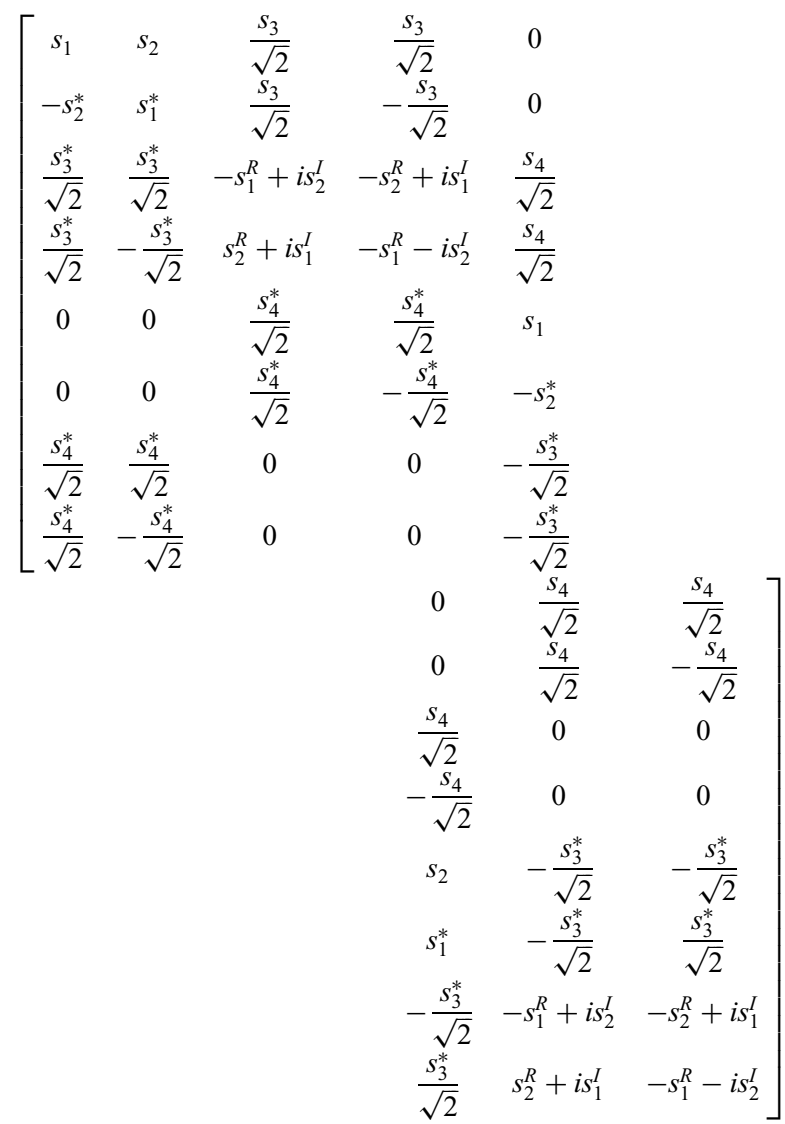


where $s_{k}^{R}$, and $s_{k}^{I}$ denote real and imaginary parts of $s_{k}$, respectively. The second design is based on $\operatorname{AOD}(8 ; 1,1,1,4 ; 1,1,1,4)$ and is of the form:

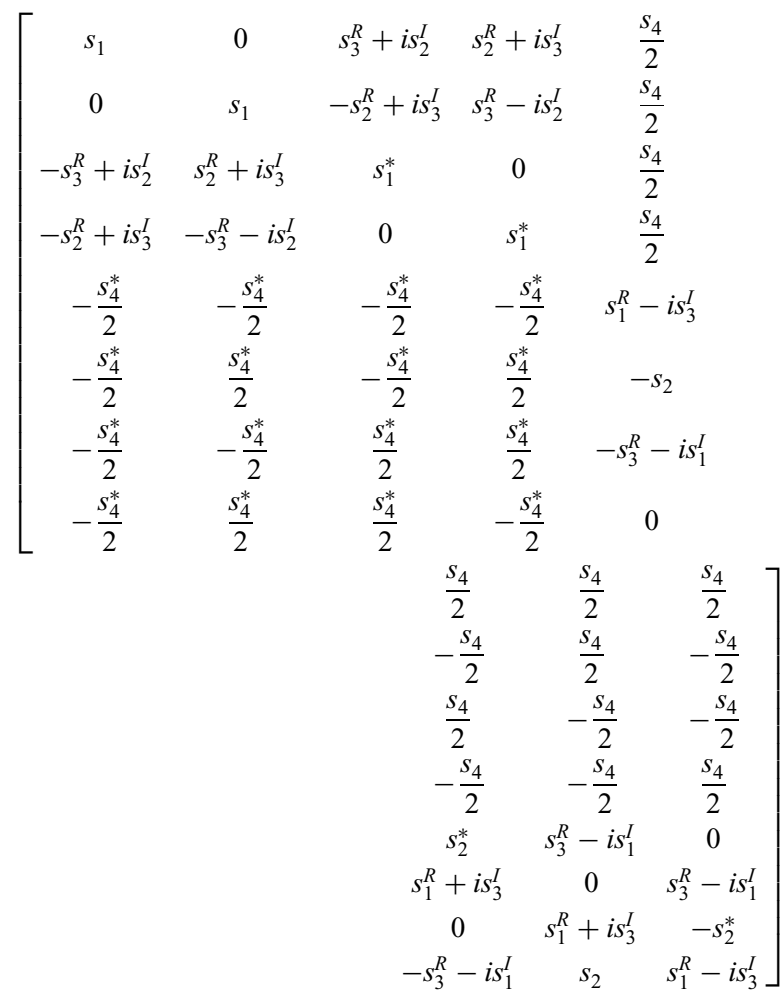

If all the symbols of both new STBCs, $S_{1}$ and $S_{2}$ defined by the CODs given by (2) and (3), respectively, are associated with QPSK complex symbols, then the bit error rate (BER) performance in a Gaussian channel of both $S_{1}$ and $S_{2}$ is exactly the same as performance of the complex orthogonal STBC of order 8 described in [3]. The achieved code rate is also the same and equal to $1 / 2$. From (2) and (3) it is visible that in $S_{1}$ and $S_{2}$ some of the symbols are transmitted in more than a single time slot per given antenna. In fact, in $S_{1}$, symbols $s_{3}$ and $s_{4}$ are transmitted twice as often as $s_{1}$ or $s_{2}$. In $S_{2}$, the symbol $s_{4}$ is transmitted four times as often as $s_{1}, s_{2}$ or $s_{3}$. Thus, by associating $s_{3}$ and $s_{4}$ in $S_{1}$ and $s_{4}$ in $S_{2}$ with symbols from multilevel complex modulation schemes and the remaining symbols in each of $S_{1}$ and $S_{2}$ with QPSK symbols, the overall code rates can be increased. Of course, there is a trade-off between the rate increase and the BER performance. This is illustrated in Figs. 1 and 2 for $S_{1}$ and $S_{2}$, respectively. In both Figures, signal-to- noise ratio (SNR) is defined by the ratio between the total power received in each symbol time slot and the noise power at the receive antenna. Multi-modulation, using QPSK, 8 PSK and 16 QAM constellations, is utilised and the bit error performance of the STBC given in [3] is also simulated to compare with the proposed codes. In simulation, the signal power per transmission in each symbol time slot is normalised to 1. Figs. 1 and 2 show that the proposed codes associated with QPSK single-modulation provide a good bit error performance. Additionally, by sacrificing 3 and $5 \mathrm{~dB}$, with respect to $\mathrm{SNR}$ at BER $=10^{-5}$, in the case of $S_{1}$, and by 2.5 and $3 \mathrm{~dB}$, in the case of $S_{2}$, one can increase the code rate from $1 / 2$ to higher code rates of $5 / 8$ and $3 / 4$, in the case of $S_{1}$, and of $9 / 16$ and $5 / 8$, in the case of $S_{2}$, respectively. Furthermore, at the same code rate, both proposed codes provide better bit error performance than the code in [3], by around $1 \mathrm{~dB}$ (QPSK + $8 \mathrm{PSK})$ and $1 \mathrm{~dB}$ (QPSK $+16 \mathrm{QAM})$, in case of $S_{1}$, and around $1.5 \mathrm{~dB}$ $(\mathrm{QPSK}+8 \mathrm{PSK})$ and $2.5 \mathrm{~dB}(\mathrm{QPSK}+16 \mathrm{QAM})$, in case of $S_{2}$, respectively, at $\mathrm{BER}=10^{-5}$.

Conclusions: We have presented two new complex orthogonal STBCs for eight transmit antennas that can provide higher data rates (up to 3/4) than other complex STBCs of the same order. This is achieved by employing multilevel modulation schemes for those code symbols that are transmitted more often than other symbols for which QPSK is used. This feature can be utilised in the design of adaptive STBC schemes, where the code rate can be traded for BER and vice versa. W

(C) IEE 2004

13 October 2003

Electronics Letters online no: 20040010

doi: 10.1049/el:20040010

Le Chung Tran, J. Seberry, Yejing Wang, B.J. Wysocki, T.A. Wysocki, Tianbing Xia and Ying Zhao (University of Wollongong, NSW 2522, Australia)

\section{References}

1 Tarokh, V., Jafarkhani, H., and Calderbank, A.R.: 'Space-time block codes from orthogonal designs', IEEE Trans. Inf. Theory, 1999, 45, (5), pp. $1456-1467$

2 Geramita, A.V., and Seberry, J.: 'Orthogonal designs, quadratic forms and Hadamard matrices', Ser. Lec. Notes Pure Appl. Math., 1979, 43 (New York and Basel, Marcel Dekker)

3 Tirkkanon, O., and Hottinen, A.: 'Square-matrix embeddable space-time block codes for complex signal constellations', IEEE Trans. Inf. Theory, 2002, 48, (2), pp. 384-395

4 Ganesan, G., and Stoica, P.: 'Space-time block codes: a maximum SNR approach', IEEE Trans. Inf. Theory, 2001, 47, (4), pp. 1650-1656 